\title{
Osteoporosis Is Associated with Deteriorating Clinical Status in Adults with Cystic Fibrosis
}

\author{
Inger Hee Mathiesen $\left(\mathbb{D},{ }^{1}\right.$ Tacjana Pressler, ${ }^{1,2}$ Peter Oturai, ${ }^{3}$ Terese Lea Katzenstein, ${ }^{1}$ \\ Marianne Skov, ${ }^{2}$ Ruth Frikke-Schmidt, ${ }^{4}$ and Mette Friberg $\mathrm{Hitz}^{5}$ \\ ${ }^{1}$ Department of Infectious Diseases, Copenhagen Cystic Fibrosis Center, Rigshospitalet, Blegdamsvej 9, 2100 Copenhagen, Denmark \\ ${ }^{2}$ Danish Pediatric Pulmonary Service, Copenhagen Cystic Fibrosis Center, Rigshospitalet, Blegdamsvej 9, 2100 Copenhagen, Denmark \\ ${ }^{3}$ Department of Clinical Physiology, Nuclear Medicine \& PET, Rigshospitalet, Blegdamsvej 9, 2100 Copenhagen, Denmark \\ ${ }^{4}$ Department of Clinical Biochemistry, Rigshospitalet, Blegdamsvej 9, 2100 Copenhagen, Denmark \\ ${ }^{5}$ Department of Medicine, Endocrine Division, Zealand University Hospital, Lykkebaekvej 1, 4600 Koege, Denmark
}

Correspondence should be addressed to Inger Hee Mathiesen; ihm@dadlnet.dk

Received 14 July 2017; Revised 22 November 2017; Accepted 18 January 2018; Published 26 March 2018

Academic Editor: Kazuhiro Shiizaki

Copyright (C) 2018 Inger Hee Mathiesen et al. This is an open access article distributed under the Creative Commons Attribution License, which permits unrestricted use, distribution, and reproduction in any medium, provided the original work is properly cited.

Background. Cystic fibrosis (CF) patients are in increased risk of osteoporosis. We aimed to determine the osteoporosis prevalence in an adult CF cohort and investigate calcium metabolic parameters and clinical status' association with bone mineral density evaluated by dual X-ray absorptiometry scan. Methods. We performed a cross section database study of adults at a tertiary CF Center. $Z$ scores were applied for patients $<50$ years of age and $T$ scores for patients $>50$ years of age. Results. One hundred twenty-five patients were included. Compared to nonosteoporotic patients, osteoporotic patients (15\%) had significantly lower percent predicted forced expiratory volume in 1 second (ppFEV1), lower body mass index, higher frequency of CF-related diabetes and chronic lung infection, and higher high-sensitive C-reactive protein and glycated hemoglobin levels. Vitamin D was not associated with any outcome. In multivariate analyses, only ppFEV1 and female gender were independently associated with $Z$ scores. Conclusions. Osteoporosis in CF occurs with deteriorating clinical status while the role of calcium metabolism seems minor. Gender specific and dysglycemic impact on bone status should be investigated further.

\section{Introduction}

As treatments for cystic fibrosis have improved, the median life expectancy has increased over the last decades [1]. However, as lifespan increases so does the risk of comorbidities. One of these is osteoporosis, and CF patients have increased risk of osteoporosis compared to age-matched controls [2,3]. Another frequent feature of CF is vitamin D deficiency $[2,3]$.

A silent disease, osteoporosis has no clinical manifestations but the consequence-osteoporotic fractures-does. Osteoporotic fractures may have severe consequences for CF patients. Low-impact fractures, for example, costa fractures from coughing may worsen their pulmonary condition as reduced coughing, due to thoracic pains, will lead to sputum stagnation and reduced airway clearance. This will favor the conditions for bacterial growth, ultimately leading to pulmonary exacerbation [4]. Furthermore, vertebral fractures can lead to anatomic changes of the thorax, which may impede or even rule out lung transplantation $[2,3,5,6]$.

Factors such as calcium metabolic alterations, malabsorption, delayed puberty, chronic inflammation, and many other conditions associated with CF $[2,7,8]$ can prevent patients from achieving peak bone mass equal to their healthy peers and increase bone loss in adulthood.

The aim of the study was to determine the prevalence of osteoporosis in a cohort of well-treated CF adults and investigate clinical and calcium metabolic parameter's association with BMD.

\section{Methods}

We performed a cross section study of adults at the Copenhagen CF Center. 
All CF patients are followed monthly with assessment of clinical status (lung function parameters, body mass index (BMI), and sputum microbiology) at the CF outpatient clinic. An annual review is performed including extensive biochemical evaluation. Clinical data and prescribed medications are prospectively registered in patient records and the CF Center database.

Patients are routinely supplemented with fat-soluble vitamins $\mathrm{A}, \mathrm{D}\left(\mathrm{D}_{3}\right)$ (2400 International Units (IU) cholecalciferol), E, and $\mathrm{K}$.

Study inclusion criteria were patients with a confirmed CF diagnosis by genotyping and/or sweat test aged $\geq 20$ years attending the Copenhagen CF Center regularly (at least 4 times a year), with at least one DXA scan between 2010 and 2015. Patients with a history of solid organ transplantation were excluded.

The following data were extracted from the CF database: weight, height, BMI (average BMI within the same year as DXA and blood samples were performed), CF genotype, gender, and age. Further, information about chronic bacterial lung infection, pancreas insufficiency, CF-related diabetes (CFRD), and lung function (ppFEV1) $[9,10]$ were obtained. From medical records, information regarding additional vitamin $\mathrm{D}_{3}$ beyond routine supplementation, contraceptives, inhaled steroids, PPI use, and bone antiresorptive treatment (bisphosphonates) were obtained.

2.1. Bone Densitometry. Bone mineral density (BMD) was determined with DXA scan (Lunar Prodigy Pro, GE Healthcare, Madison, WI, USA). BMD was measured in the lumbar spine (L2-L4) and in the right and left femoral neck and trochanter regions. All measurements were performed by trained technicians and reviewed by trained physicians, and the same scanner was used for all measurements. Results were expressed as BMD $\left(\mathrm{g} / \mathrm{cm}^{2}\right), T$ scores (the number of standard deviations a given BMD value differs from the mean value of young healthy adults), and $Z$ scores (the number of standard deviations a given BMD value differs from the mean of healthy age- and gender-matched controls). Scores were calculated with a German normal reference material provided by the manufacturer. International Society for Clinical Densitometry (ISCD) criteria for younger males $<50$ years of age and premenopausal females were applied, defining $Z$ scores $<-2$ as BMD below expected range for age and $Z$ scores $\geq-2$ as BMD within expected range for age [11], which was then defined as osteoporosis and BMD within the normal range, respectively. Participants above 50 years of age were grouped according to WHO criteria definitions [12] with $T$ scores $\leq-2.5$ defining osteoporosis. Left femur was used in analyses unless otherwise stated.

2.2. Blood Tests. From an extended blood panel drawn the same year as DXA scan was performed, the following parameters were available: vitamin $\mathrm{D}$ (25OHD) (vitamin $\mathrm{D}_{3}$ + vitamin $\mathrm{D}_{2}$ ), alkaline liver transaminase (ALT), alkaline phosphatase, hemoglobin A1c (hbA1c), creatinine, thyroid-stimulating hormone (TSH), total immunoglobulin $\mathrm{G}$ (IgG), albumin, magnesium $\left(\mathrm{Mg}^{2+}\right)$, and phosphate $\left(\mathrm{PH}^{-}\right)$. Follicle-stimulating hormone (FSH), luteinizing hormone (LH), total testosterone, total estradiol, parathyroid hormone (PTH), total calcium, and high-sensitive C-reactive protein (hsCRP) were analyzed from frozen serum samples collected at the same sample date as the extended blood panel. All frozen samples were stored at $-80^{\circ} \mathrm{C}$ until analysis. Total testosterone, total estradiol, FSH, LH, and PTH were measured by electrochemiluminescence immunoassays (ECLIA) (Cobas, Roche, Switzerland). Coefficient of variation for these was PTH 7\%, FSH and $\mathrm{LH} \mathrm{7 \% ,} \mathrm{total} \mathrm{testoster-}$ one $6 \%$ and $5 \%$ at levels $3 \mathrm{nmol} / 1$ and $35 \mathrm{nmol} / \mathrm{l}$, respectively, and total estradiol $11 \%$ and $7 \%$ at levels $0.2 \mathrm{nmol} / \mathrm{l}$ and $2.5 \mathrm{nmol} / \mathrm{l}$, respectively.

2.3. Lung Function Test. Lung function tests were performed at every outpatient visit according to American Thoracic Society/European Respiratory Society (ATS/ERS) guidelines [9, 10] using Jaeger Master Screen Pro (CareFusion, Hochberg, Germany). For the study, mean ppFEV1 of all measurements within the year of DXA scan was calculated and used.

2.4. Statistical Analysis. Descriptive statistics are presented as median and interquartile range (IQR), mean and standard deviation (SD) or percentage (\%) as appropriate. ANOVA, parametric/nonparametric $T$-test according to distribution, or chi-square test were used to compare groups (vitamin D levels, men versus women, normal BMD versus osteoporosis). When groups were very unequal in sample size, Welch $T$-test was used. Univariate regression analysis was performed to evaluate associations between bone measurements and factors. Nonnormal distributed data were log10 transformed or square rooted. Finally, a predefined multivariate linear regression (MLR) model was performed for both $T$ and $Z$ scores containing the variables gender, ppFEV1, BMI, chronic infection (no/yes), hsCRP, 25OHD, and estradiol. For regression analyses, both $Z$ and $T$ scores were used as much previous literature in adults is based on $T$ scores. All analyses were performed with SPSS ver. 22. A $p$ value $<0.05$ was considered statistically significant.

The study protocol was approved by the Local Ethics Committee (H-15008060) and Local Data Protection Agency (RH-2015-186, I-suite number 04107).

\section{Results}

Of 172 nonlung transplanted patients $\geq 20$ years of age, 125 patients fulfilled the inclusion criteria and were included.

Baseline characteristics are depicted in Table 1. Ten patients were scanned in 2012, 31 patients in 2013, 53 patients in 2014, and 31 patients in 2015.

\section{Vitamin D}

The median (IQR) 25OHD level in the cohort was $49.5 \mathrm{nmol} /$ 1 (32-71) (Table 2). Twenty-four patients (19\%) had 25OHD levels $\geq 75 \mathrm{nmol} / \mathrm{l}$. Of those, twelve (50\%) received additional vitamin $\mathrm{D}_{3}$ (mean 400 IU daily, IQR: 400 IU-800 IU) in addition to routine supplementation of $2400 \mathrm{IU}$ daily. In total, forty seven patients were prescribed additional $\mathrm{D}_{3}$ substitution besides routine supplementation but there was no 
TABLE 1: Baseline characteristics.

\begin{tabular}{lc}
\hline & Overall \\
\hline ppFEV1 (SD) & $67 \pm 23$ \\
BMI kg/m ${ }^{2}(\mathrm{SD})$ & $22.3 \pm 3.5$ \\
Age, years (SD) & $33.1 \pm 10$ \\
Males, $n$ (\%) & $62(50.4)$ \\
Females, $n$ (\%) & $63(49.6)$ \\
Pancreas insufficiency, $n(\%)$ & $120(97)$ \\
Homozygous F508del, $n(\%)$ & $89(71)$ \\
CF-related diabetes, $n(\%)$ & $51(41)$ \\
CF-related diabetes, duration in years (IQR) & $10(6-18)$ \\
Chronic infection, $n$ (\%) & $101(81)$ \\
Steroid inhalation therapy, $n(\%)$ & $55(44)$ \\
Additional $D_{3}$ supplementation, $n(\%)$ & $47(38)$ \\
Proton pump inhibitors, $n(\%)$ & $44(35)$ \\
Spine BMD & $1.145 \pm 0.158$ \\
Femoral BMD & $0.974 \pm 0.197$ \\
$T$ score & $-0.981 \pm 1.260$ \\
$Z$ score & $-0.748 \pm 1.110$ \\
\hline
\end{tabular}

ppFEV1: percent predicted forced expiratory volume in 1 second; BMI: body mass index; extra $\mathrm{D}_{3}$ supplementation: additional $\mathrm{D}_{3}$ supplementation on top of routine supplementation; BMD: bone mineral density; $T$ score: lowest $T$ score at any site for cases; $Z$ score: lowest $Z$ score at any site for cases; IQR: interquartile range; SD: standard deviation.

significant difference in 25OHD levels between receivers and nonreceivers of extra $\mathrm{D}_{3}$, mean levels $51 \mathrm{nmol} / \mathrm{l}$ and $53 \mathrm{nmol} / \mathrm{l}, p=0.7$, respectively. Overall, the 25OHD level was significantly higher in patients, who had their 25OHD levels measured during May-October than during the winter months (mean levels $59.6 \mathrm{nmol} / \mathrm{l}$ versus $47.1 \mathrm{nmol} / \mathrm{l}, p=0.02)$. There was no seasonal variation in other calcium metabolic parameters, that is, PTH, total calcium, $\mathrm{Mg}^{2+}$, or $\mathrm{PH}^{-}$(Figure 1).

Patients were subgrouped according to 25OHD levels as deficient $<25 \mathrm{nmol} / \mathrm{l}$, insufficient $>25-50 \mathrm{nmol} / \mathrm{l}$, and replete $>50 \mathrm{nmol} / \mathrm{l}$. There was no statistical significant difference in baseline characteristics. Parathyroid hormone was significantly higher in the deficiency group compared to the insufficient group (mean difference 1.35, 95\% CI 0.27-2.43, $p=0.006$ ) and replete group (mean difference $1.43,95 \% \mathrm{CI}$ $0.52-2.34, p=0.001$ ). Total calcium levels did not differ between groups, but $\mathrm{PH}^{-}$was significantly lower in the deficiency group compared to the replete group (mean difference between groups 0.13 , 95\% CI: 0.03-0.23, $p=0.005$ ). However, both mean PTH values and mean $\mathrm{PH}^{-}$values were within normal range in all vitamin $\mathrm{D}$ groups (Table 3 ). Neither $\mathrm{Mg}^{2+}$ nor alkaline phosphatase was significantly different between groups.

\subsection{Hormones. Hormones were analyzed gender specific.}

Amongst women, it was not possible to retrieve data regarding menstrual cycle, possible amenorrhea, or peri/ postmenopausal stage. Six women were according to medical records taking oral contraceptives and excluded from further hormonal analyses. Hormonal levels are depicted in Table 4. The majority of women below the age of 50 had estradiol levels below $0.5 \mathrm{nmol} / 1$.

In men, median estradiol level was $0.1 \mathrm{nmol} / 1(0.09-$ $0.23)$. Overall median testosterone for men $<50$ years of age was $2.6(0.73-13.46)$.

4.2. Bone Status Assessment. The overall DXA scan results are depicted in Table 1. Nineteen patients (15\%) had osteoporosis, fifteen patients (12\%) had $Z$ scores below the expected range for age $(Z$ scores $<-2)$, and four patients had $T$ scores $\leq-2.5$ and were above 50 years of age. Mean $Z$ scores of the overall cohort were significantly lower compared to the mean healthy age-matched general population and mean difference between groups was -0.748 (95\% CI: -0.95 to $-0.55), p<0.001$. Patients homozygous for the F508del had significantly lower BMD than nonhomozygous patients. For femoral BMD, mean difference between groups was -0.09 (95\% CI: -0.16 to -0.01 ), $p=0.03$, and for lumbar BMD, mean difference between groups was -0.07 (95\% CI: -0.13 to -0.01$), p=0.02$.

Compared to the group with BMD values within the normal range, osteoporotic patients had significantly lower average ppFEV1 $(p<0.001)$, BMI $(p<0.001)$, and albumin $(p=0.01)$, but there was no significant difference in age (34 years versus 31 years, $p=0.19$ ) or gender distribution in groups $(p=0.16)$ (Table 5$)$.

The osteoporosis group was more frequently chronically infected $(p=0.02)$ and had higher hsCRP levels $(p=0.04)$, but there was no difference in IgG between groups.

Patients with osteoporosis also had a higher frequency ( $p=0.03)$ but not a longer duration of CFRD $(p=0.06)$, and hbA1c was significantly higher compared to the group with $\mathrm{BMD}$ values within the normal range $(p<0.001)$.

ALT was higher among patients with osteoporosis, but no other calcium metabolic-, liver-, and kidney parameters differed between the groups (Table 2).

There was no difference in frequency of PPI or steroid IH usage between groups (Table 5).

Estradiol levels were significantly lower in osteoporotic women compared to women with BMD within the normal range (Table 4 ). In men, median estradiol levels were at the lower limit of the reference interval $(0.09 \mathrm{nmol} / \mathrm{l})$ for both groups; no sex hormone levels differed between osteoporotic and nonosteoporotic men.

4.3. Regression Analyses. Univariate associations between bone status and clinical and paraclinical parameters are presented in Table 6 . In multivariate regression analysis (MLR), femoral $Z$ and $T$ scores were independently associated with ppFEV1 and chronic infection. Spine $Z$ and $T$ scores were independently associated with ppFEV1, chronic infection, and female gender, and spine $T$ score was also with BMI (Table 7).

\section{Discussion}

In a well-treated and closely monitored cohort of adult CF patients, we found that $15 \%$ had osteoporosis, which is 
TABLE 2: Calcium metabolic and biochemical differences between groups.

\begin{tabular}{|c|c|c|c|c|c|}
\hline & Normal range & Overall & BMD within the normal range & Osteoporosis & $p$ between groups \\
\hline $25 \mathrm{OHD}(n=121)$ & $(>50 \mathrm{nmol} / \mathrm{l})$ & $49(32-71)$ & $49(34-71)$ & $32(16-71)$ & 0.39 \\
\hline Calcium $(n=125)$ & $(2.15-2.51 \mathrm{mmol} / \mathrm{l})$ & $2.21(2.12-2.31)$ & $2.22(2.13-2.32)$ & $2.12(2.02-2.28)$ & 0.26 \\
\hline $\mathrm{PTH}(n=125)$ & $(1.6-6.9 \mathrm{pmol} / \mathrm{l})$ & $2.12(1.36-2.91)$ & $2.12(1.37-2.76)$ & $2.13(1.6-4.86)$ & 0.18 \\
\hline $\mathrm{Mg}^{2+}(n=117)$ & $(0.71-0.94 \mathrm{mmol} / \mathrm{l})$ & $0.8(0.75-0.84)$ & $0.8(0.76-0.84)$ & $0.77(0.7-0.87)$ & 0.18 \\
\hline $\mathrm{PH}^{-}(n=117)$ & $(0.71-1.53 \mathrm{mmol} / \mathrm{l})$ & $1.07(0.96-1.18)$ & $1.07(0.96-1.16)$ & $1.11(0.94-1.29)$ & 0.44 \\
\hline A phosphatase $(n=123)$ & $(35-105 \mathrm{U} / \mathrm{l})$ & $94(77-122)$ & $89(76-120)$ & $112(83-170)$ & 0.11 \\
\hline Zink $(n=110)$ & $(10-19 \mu \mathrm{mol} / \mathrm{l})$ & $13(11-14)$ & $13(11-15)$ & $11(9-13)$ & 0.13 \\
\hline Albumin $(N=122)$ & $(36-48 \mathrm{~g} / \mathrm{l})$ & $38(34-42)$ & $39(34-42)$ & $37(30-39)$ & 0.02 \\
\hline $\operatorname{IgG}(n=121)$ & $(6.1-14.9 \mathrm{~g} / \mathrm{l})$ & $11.2(9-13.7)$ & $11.2(9.00-13.25)$ & $12.00(8.4-14.90)$ & 0.46 \\
\hline hsCRP $(n=125)$ & $(<3.00 \mathrm{mg} / \mathrm{l})$ & $2.34(1.00-6.97)$ & $2.10(0.93-6.94)$ & $4.52(2.80-8.22)$ & 0.04 \\
\hline Urea $(n=124)$ & $(3.2-8.1 \mathrm{mmol} / \mathrm{l})$ & $4.7(3.93-6.18)$ & $4.70(3.90-6.10)$ & $5.00(4.20-6.80)$ & 0.84 \\
\hline Creatinine $(n=124)$ & $(60-105 \mu \mathrm{mol} / \mathrm{l})$ & $70(60-83)$ & $69(60-81)$ & $73(63-104)$ & 0.13 \\
\hline $\operatorname{ALT}(n=123)$ & $(10-70 \mathrm{U} / \mathrm{l})$ & $26(19-39)$ & $26(19-42)$ & $28(19-31)$ & 0.02 \\
\hline $\mathrm{LDH}(n=122)$ & $(115-255 \mathrm{U} / \mathrm{l})$ & $158(142-176)$ & $159(142-179)$ & $152(140-170)$ & 0.43 \\
\hline $\operatorname{hbA1c}(n=122)$ & $(<48 \mathrm{mmol} / \mathrm{mol})$ & $41(36-53)$ & $40(36-49)$ & $55(40-78)$ & 0.007 \\
\hline $\mathrm{TSH}(n=122)$ & $\left(0.65-4.80 \times 10^{-3} \mathrm{IU} / \mathrm{l}\right)$ & $1.85(1.24-2.58)$ & $1.87(1.25-2.61)$ & $1.81(0.92-2.56)$ & 0.90 \\
\hline
\end{tabular}

All data presented as median and interquartile range (IQR). 25OHD: vitamin D; $\mathrm{PTH}$ : parathyroid hormone; $\mathrm{Mg}^{2+}$ : magnesium; $\mathrm{PH}^{-}$: phosphate; A phosphatase: alkaline phosphatase; IgG: immunoglobulin G; hsCRP: high-sensitive C-reactive protein; ALT: alanine aminotransferase; LDH: lactate dehydrogenase; hbAlc: hemoglobin Alc; TSH: thyroid-stimulating hormone; m: milli; $\mu$ : micro; n: nano; pmol: picomol; l: liter; IU: international units; g: gram.

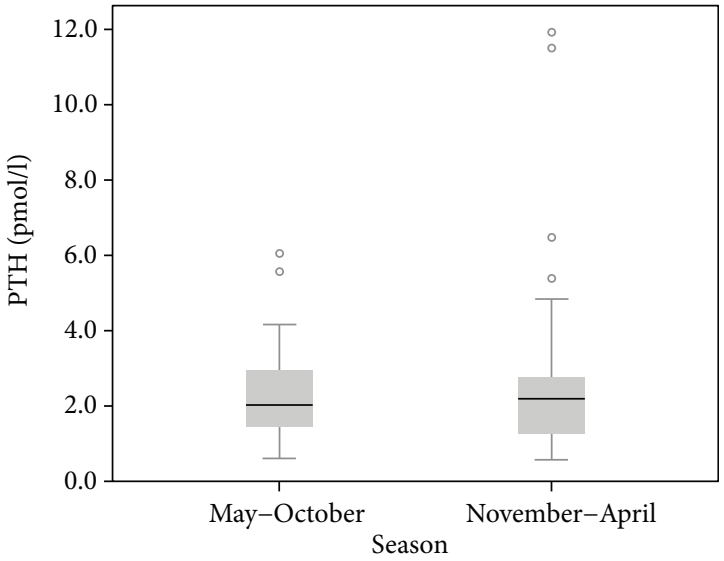

(a)

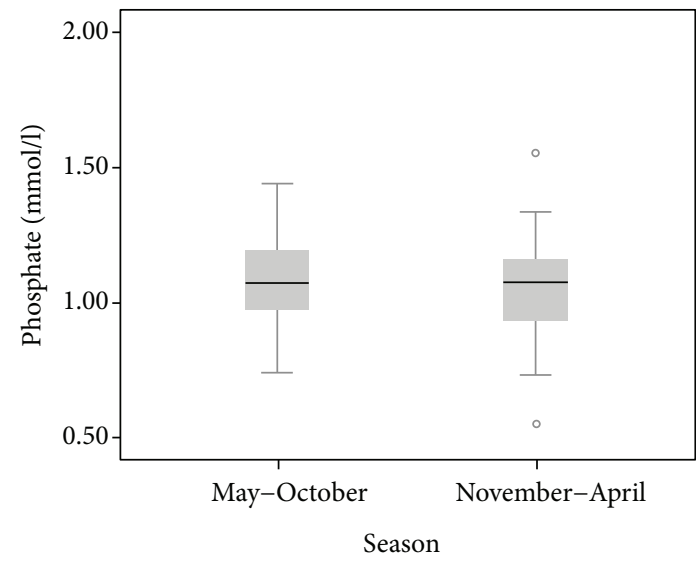

(c)



(b)

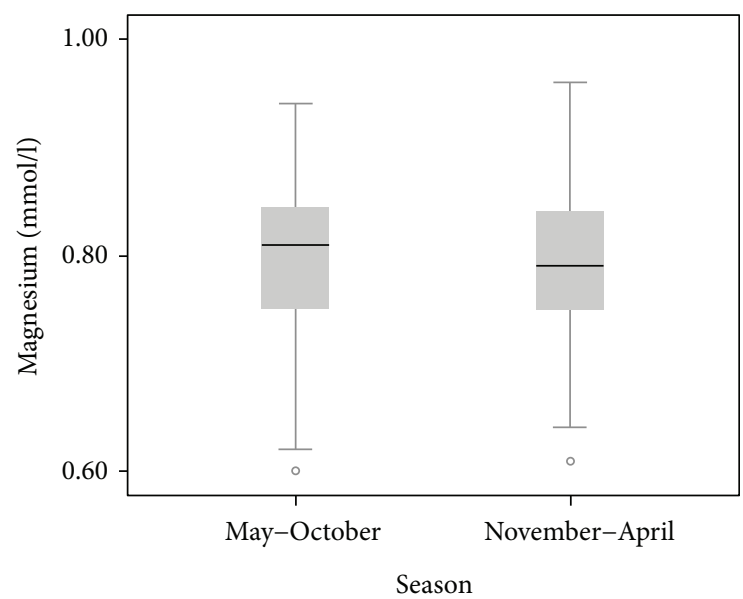

(d)

Figure 1: Seasonal variation in calcium metabolic parameters. 
TABLE 3: Calcium metabolic parameters by vitamin D status.

\begin{tabular}{|c|c|c|c|c|c|}
\hline & Normal range & Deficient & Insufficient & Replete & $p$ \\
\hline Calcium & $(2.15-2.51 \mathrm{mmol} / \mathrm{l})$ & $2.17(0.16)$ & $2.21(0.14)$ & $2.23(0.17)$ & 0.27 \\
\hline Phosphate & $(0.71-1.53 \mathrm{mmol} / \mathrm{l})$ & $1.16(0.2)$ & $1.08(0.16)$ & $1.02(0.16)$ & 0.006 \\
\hline PTH & $(1.6-6.9 \mathrm{pmol} / \mathrm{l})$ & $3.5(3.12)$ & $2.18(0.86)$ & $2.10(1.10)$ & 0.001 \\
\hline Magnesium & $(0.71-0.94 \mathrm{mmol} / \mathrm{l})$ & $0.80(0.07)$ & $0.80(0.06)$ & $0.79(0.08)$ & 0.34 \\
\hline Alkaline phosphatase & $(35-105 \mathrm{U} / \mathrm{l})$ & $129.13(87)$ & $105.00(43)$ & $107.00(65)$ & 0.30 \\
\hline
\end{tabular}

ANOVA $p$ value. Values are displayed as mean (SD).

TABLE 4: Sex hormones in males and females.

\begin{tabular}{lccccc}
\hline & Normal range & Overall & BMD within the normal range & Osteoporosis & $p$ between groups \\
\hline Males $(n=58)$ & & & & & \\
FSH & $(<11 \mathrm{IU} / \mathrm{l})$ & $5.36(3.07-9.18)$ & $6.36(3.09-10.62)$ & $4.10(2.96-5.45)$ & 0.68 \\
LH & $(1.7-8.6 \mathrm{IU} / \mathrm{l})$ & $4.89(3.79-6.74)$ & $5.22(3.96-7.32)$ & $4.29(2.69-6.02)$ & 0.71 \\
Testosterone & $(8.6-29 \mathrm{nmol} / \mathrm{l})$ & $14.65(10.47-17.79)$ & $15.05(11.32-18.13)$ & $9.38(9.02-12.07)$ & $0.09(0.09-0.11)$ \\
Estradiol & $(0.09-0.22 \mathrm{nmol} / \mathrm{l})$ & $0.09(09-.0 .11)$ & $0.09(0.09-0.12)$ & 0.40 \\
Females $(n=55)$ & & & & $5.12(3.69-6.29)$ \\
FSH & $(1.9-20 \mathrm{IU} / \mathrm{l})$ & $5.04(3.77-6.58)$ & $4.82(3.77-6.70)$ & $6.26(2.10-7.97)$ \\
LH & $(1.0-95.6 \mathrm{IU} / \mathrm{l})$ & $5.65(2.65-8.81)$ & $5.57(2.61-8.92)$ & 0.51 \\
Testosterone & $(0.4-1.7 \mathrm{nmol} / \mathrm{l})$ & $0.83(0.47-1.39)$ & $0.81(0.42-1.35)$ & $1.39(0.61-3.21)$ \\
Estradiol & $(0.05-1.46 \mathrm{nmol} / \mathrm{l})$ & $0.15(0.11-0.33)$ & $0.19(0.11-0.35)$ & $0.12(0.09-0.13)$ & 0.61 \\
\hline
\end{tabular}

All data presented as median and interquartile range (IQR). FSH: follicle-stimulating hormone; LH: luteinizing hormone; n: nano; l: liter; IU: international units.

TABLE 5: Difference in baseline characteristics between osteoporotic and nonosteoporotic groups.

\begin{tabular}{|c|c|c|c|}
\hline & $\begin{array}{l}\text { BMD within the normal range } \\
\qquad(N=106)\end{array}$ & $\begin{array}{l}\text { Osteoporosis } \\
\quad(N=19)\end{array}$ & $p$ between groups \\
\hline ppFEV1 (IQR) & $70(52-87)$ & $44(27-65)$ & $<0.001$ \\
\hline $\mathrm{BMI} \mathrm{kg} / \mathrm{m}^{2}$ (IQR) & $22.5(20.4-24.5)$ & $19.6(18.8-20.7)$ & $<0.001$ \\
\hline Age, years (IQR) & $30(24-39)$ & $34(25-47)$ & 0.52 \\
\hline Males, $n(\%)$ & $55(52)$ & $7(37)$ & 0.27 \\
\hline Females, $n(\%)$ & $51(48)$ & $12(63)$ & - \\
\hline Pancreas insufficiency, $n(\%)$ & $101(95)$ & $19(100)$ & ns \\
\hline Homozygous F508del, $n(\%)$ & $74(70)$ & $16(84)$ & 0.38 \\
\hline CF-related diabetes, $n(\%)$ & $43(39)$ & $8(53)$ & 0.03 \\
\hline CF-related diabetes, duration in years (IQR) & $9(6-16)$ & $15(10-25)$ & 0.06 \\
\hline Chronic infection, $n(\%)$ & $82(77)$ & $19(100)$ & 0.02 \\
\hline Steroid inhalation therapy, $n(\%)$ & $52(47)$ & $3(20)$ & 0.06 \\
\hline Additional $\mathrm{D}_{3}$ supplementation, $n(\%)$ & $36(34)$ & $11(58)$ & 0.05 \\
\hline Proton pump inhibitors, $n(\%)$ & $41(39)$ & $2(16)$ & 0.07 \\
\hline
\end{tabular}

ppFEV1: percent predicted forced expiratory volume in 1 second; BMI: body mass index; additional $\mathrm{D}_{3}$ supplementation: additional $\mathrm{D}_{3}$ supplementation in addition to routine supplementation; BMD: bone mineral density; IQR: interquartile range.

comparable to other CF cohorts [5]. Z scores were significantly lower compared to a healthy, age-matched population, and bone density was independently associated with ppFEV1, chronic infection, and female gender.

Consistent with previous findings, ppFEV1 was significantly associated with BMD $[5,6,13,14]$. As well, BMI and albumin were significantly lower while CFRD and chronic infection frequencies were significantly higher in osteoporotic patients compared to patients with BMD values within the normal range. And patients homozygous for the F508del mutation had significant lower BMD compared to patients bearing only one or no F508del mutation. These findings all represent disease severity and progression confirming that clinical status is an important factor for 
TABLE 6: Univariate regression between spine and femoral $T$ and $Z$ scores and biochemical and clinical parameters.

\begin{tabular}{|c|c|c|c|c|c|c|c|c|}
\hline & \multicolumn{2}{|c|}{ Spine $Z$ score } & \multicolumn{2}{|c|}{ Femoral $Z$ score } & \multicolumn{2}{|c|}{ Spine $T$ score } & \multicolumn{2}{|c|}{ Femoral $T$ score } \\
\hline & B & $95 \% \mathrm{CI}$ & B & $95 \% \mathrm{CI}$ & B & $95 \% \mathrm{CI}$ & B & $95 \% \mathrm{CI}$ \\
\hline Albumin & 0.03 & $(-0.01-0.07)$ & ${ }^{*} 0.05$ & $(0.01-0.09)$ & ${ }^{*} 0.05$ & $(0.002-0.09)$ & ${ }^{*} 0.08$ & $(0.03-0.12)$ \\
\hline PTH & -0.52 & $(-1.31-0.27)$ & ${ }^{*}-0.19$ & $(-1.59$ to -0.02$)$ & -0.69 & $(-1.46-0.28)$ & $*-0.23$ & $(-0.36$ to -0.09$)$ \\
\hline $25 \mathrm{OHD}$ & 0.001 & $(-0.01-0.01)$ & 0.02 & $(-0.08-0.13)$ & 0.04 & $(-0.07-0.16)$ & 0.03 & $(-0.09-0.15)$ \\
\hline Calcium & 0.84 & $(-0.50-2.18)$ & *1.36 & $(0.004-2.67)$ & 1.41 & $(-0.06-2.88)$ & *1.93 & $(0.41-3.47)$ \\
\hline hbA1c & $*-0.25$ & $(-0.44$ to -0.05$)$ & ${ }^{*}-0.38$ & $(-0.57$ to -0.18$)$ & $*-0.35$ & $(-0.56$ to -0.13$)$ & $*-0.46$ & $(-0.69$ to -0.26$)$ \\
\hline hsCRP & -0.36 & $(-0.75-0.32)$ & -0.62 & $(-1.01$ to -0.23$)$ & -0.38 & $(-0.81-0.05)$ & $*-0.69$ & $(-1.14$ to -0.25$)$ \\
\hline ppFEV1 & ${ }^{* *} 0.02$ & $(0.01-0.02)$ & ${ }^{* *} 0.03$ & $(0.02-0.03)$ & ${ }^{* *} 0.02$ & $(0.01-0.03)$ & ${ }^{* * *} 0.03$ & $(0.03-0.04)$ \\
\hline BMI & 0.05 & $(-0.01-0.11)$ & ${ }^{*} 0.06$ & $(0.003-0.12)$ & ${ }^{* *} 0.13$ & $(0.07-0.2)$ & ${ }^{* *} 0.12$ & $(0.05-0.20)$ \\
\hline
\end{tabular}

${ }^{*} p<0.05 ;{ }^{* *} p<0.001$

TABle 7: Multivariate Linear Regression for spine and femoral T and Z score.

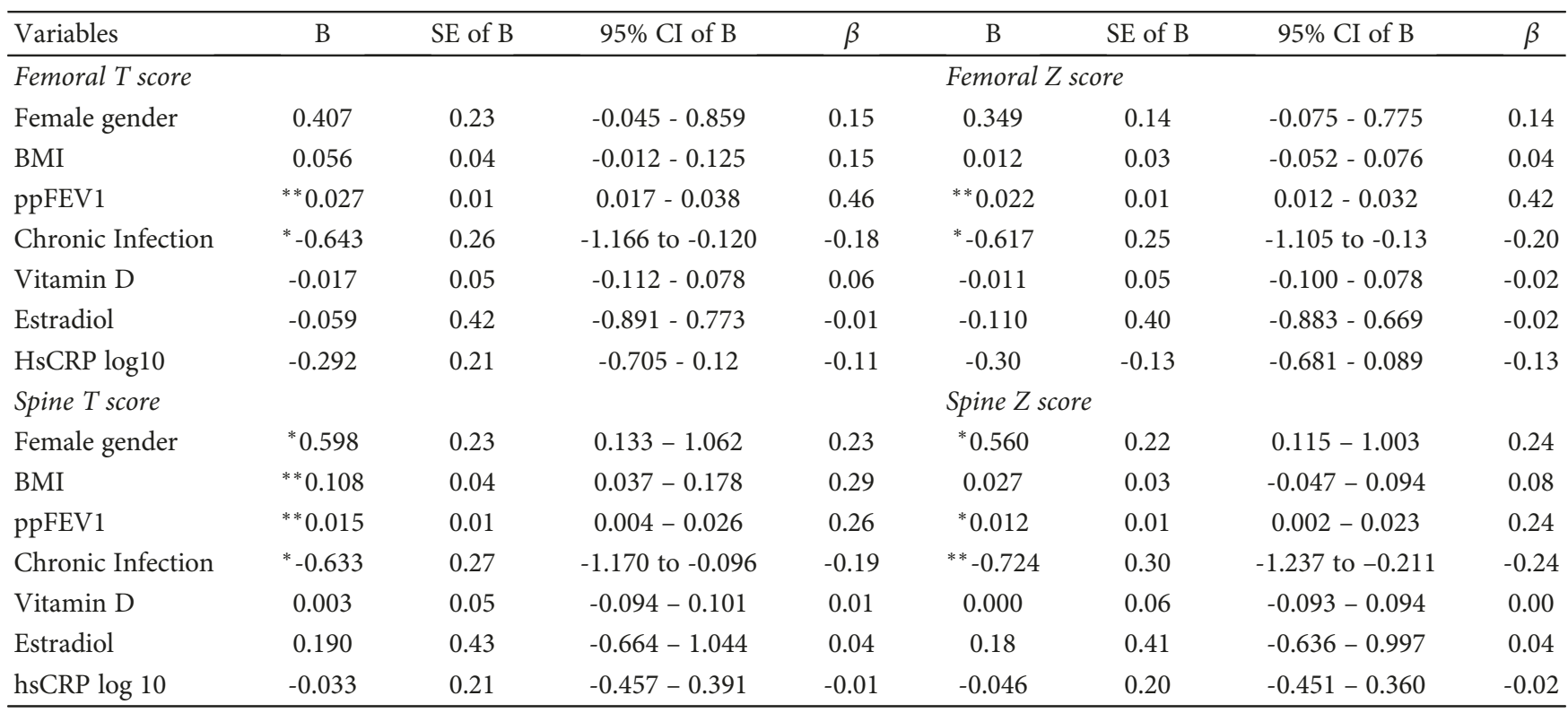

${ }^{*} p<0.05 .{ }^{* *} p<0.01$. Vitamin D is square rooted and hsCRP $\log 10$ transformed. Model fit: Femoral T score: $R^{2} 0.39$, adj. $R^{2} 0.36, F(7 / 113)=10.71, p<0.001$. Femoral $Z$ score: $R^{2} 0.27$, adj. $R^{2} 0.32, F(7 / 113)=7.61, p<0.001$. Spine $T$ score: $R^{2} 0.31$, adj. $R^{2} 0.26, F(7 / 113)=7.15, p<0.001$. Spine $Z$ score: $R^{2} 0.22$, adj. $R^{2} 0.17, F(7 / 113)=4.58, p<0.001$.

impaired bone strength in CF [13-16]. The fact that mean $Z$ score was significantly below the average healthy mean also justifies more frequent monitoring of BMD in CF populations in order to identify patients at increased risk.

Cross-sectional studies in CF and other respiratory diseases $[17,18]$ have observed findings similar to ours between decreased BMD and lung function, but it is not yet determined, whether it is the decreasing lung function itself or other factors induced by declining FEV1, which mediates the decreased BMD. In CF, a suspected link between lung function and decreasing BMD is systemic inflammation. Studies have described associations between pulmonary exacerbations, increased osteoclast maturation and activity $[19,20]$, and increased levels of inflammatory cytokines known to promote bone resorption, for example, IL-6, IL-1, and TNF $\alpha[21,22]$. The significant and independent association of chronic infection with femoral $Z$ score in our study and the higher hsCRP levels in osteoporotic patients support the relation between inflammation and bone loss.

The median 25OHD levels were considerably lower than Endocrine Society [23] and CFF [24] recommendations, and contrary to established pathogenetic understanding of decreased bone strength, there was no difference in 25OHD across between osteoporotic and nonosteoporotic groups. Noteworthy is the difference between summer and winter levels indicating that exposure to UVB radiation may be an effective way of increasing vitamin $\mathrm{D}$ levels bypassing malabsorption from the gut. The seasonal variation is also noted in other CF studies $[25,26]$ and may explain why it is difficult to determine a link between BMD and 25OHD levels. CF patients though, especially when chronically infected and deteriorating in lung function, are subject to a heavy treatment burden, and several studies of adherence to therapy in CF have consistently shown that therapy compliance often 
is as low as $50 \%$ of prescribed medications [27, 28]; this may further obscure a relationship between prescribed vitamin D doses and blood levels measured.

After all, our-as well as others'-findings [29-31] indicate that the role of vitamin D in CF bone disease may be minor compared to other complications negatively affecting bone mass such as clinical status and possibly inflammatory bone loss.

That said, intervention studies investigating bone status longitudinally have used inadequate ergocalciferol $\left(D_{2}\right)$ /cholecalciferol $\left(D_{3}\right)$ doses of less than $3000 \mathrm{IU} /$ day [31], while at present, there is consensus that oral doses of $50,000 \mathrm{IU} \mathrm{D}_{3}$ weekly for at least eight weeks are likely needed to significantly increase $25 \mathrm{OHD}$ levels above $75 \mathrm{nmol} / \mathrm{l}$ in vitamin D-deficient CF patients $[8,23,32]$.

Interestingly, osteoporotic patients had higher prevalence of CFRD and poorer glycemic control (hbAlc) compared to patients with normal $\mathrm{BMD}$, and there was a trend towards longer duration of CFRD in the osteoporotic group. There might be several ways in which CFRD contributes to CF bone disease. A recent study demonstrated elevated levels of receptor of advanced glycation end products (RAGE) and advanced glycation end products (AGE) in CF patients with CFRD compared to CF patients without CFRD and healthy controls [33]. While RAGE can enhance bone resorption through stimulation of proinflammatory cytokines and oxidative stress species [34], AGE cross-linking in bone could render CF bones more susceptible to fracture [35]. Further, osteoblast function/formation could be affected [36], as insulinopenia, which is present in CFRD, has been shown to cause impaired fracture healing [37] and bone formation deficits [38] in rodent models. The importance of these mechanisms in CF bone disease is yet to be determined.

Male patients had completely suppressed estradiol levels in both the osteoporotic and nonosteoporotic group despite estradiol being the most important sex hormone for bone in males as well as females [39]. The seemingly low testosterone levels point to male hypogonadism, which in conjunction with the completely suppressed estradiol, indicate possible sex hormone alterations, which should be investigated further together with its possible impact on BMD in CF males.

We acknowledge that there are limitations to our study. We did not have reliable information about oral/intravenous corticosteroid use which would have allowed evaluation of systemic steroids on BMD in the cohort. However, these are generally only used for intermittent worsening of $\mathrm{CF}$ arthritis or treatment of allergic bronchopulmonary aspergillosis. Hypothetically, though, such repeated high-dose prednisone in adolescence could have a negative impact on peak bone mass accrual making a subgroup more susceptible to loss of bone mass in adulthood.

Neither was it possible to measure free fractions of sex hormones, obtain history of menstrual cycle or symptoms of hypogonadism from patient records, preventing any final conclusions about sex hormones' impact on CF bone status. Finally, we did not have any radiographic data or patient history to determine correlation between any osteoporotic fractures and BMD, a relationship which is being questioned over the recent years as peripheral quantitative computed tomography scans have shown altered microarchitecture in CF bone independently of BMD [40].

In conclusion, CF patients develop impaired BMD associated with deteriorating clinical status. It is therefore important to identify these individuals at risk and ensure regular DXA scans and optimize treatment of modifiable risk factors of osteoporosis. Although the skeleton is the body's calcium storage, there was little indication that alterations in calcium metabolism significantly impact bone status, despite median vitamin D levels being well below recommended values. Long-term high-dose vitamin D studies are needed to clarify the role of $25 \mathrm{OHD}$ in CF bone disease and to which extent it may have an effect on BMD longitudinally. Sex hormonal and dysglycemic impact on bone status should be investigated further.

\section{Disclosure}

Results were partly presented in abstract and poster form at the NACFC 2016, Orlando, USA (doi: 10.1002/ppul.23576; abstract number 653).

\section{Conflicts of Interest}

The authors declare that there is no conflict of interest regarding the publication of this article.

\section{References}

[1] Cystic Fibrosis Foundation Patient Registry, Annual Data Report, Bethesda, MD, USA, 2015, https://www.cff.org/OurResearch/CF-Patient-Registry/2015-Patient-Registry-AnnualData-Report.pdf.

[2] A. P. Gore, S. H. Kwon, and A. E. Stenbit, "A roadmap to the brittle bones of cystic fibrosis," Journal of Osteoporosis, vol. 2011, Article ID 926045, 10 pages, 2011.

[3] M. Hudson, A. Bush, and D. Geddes, Cystic Fibrosis, Taylor \& Francis group, LLC, Boca Raton, FL, USA, 3rd edition, 2007.

[4] A. M. Jones, M. E. Dodd, A. K. Webb, and P. L. Selby, “Acute rib fracture pain in CF,” Thorax, vol. 56, no. 10, p. 819, 2001.

[5] M. Rossini, A. Del Marco, F. Dal Santo et al., "Prevalence and correlates of vertebral fractures in adults with cystic fibrosis," Bone, vol. 35, no. 3, pp. 771-776, 2004.

[6] S. P. Conway, A. M. Morton, B. Oldroyd et al., "Osteoporosis and osteopenia in adults and adolescents with cystic fibrosis: prevalence and associated factors," Thorax, vol. 55, no. 9, pp. 798-804, 2000.

[7] K. Redlich and J. S. Smolen, "Inflammatory bone loss: pathogenesis and therapeutic intervention," Nature Reviews Drug Discovery, vol. 11, no. 3, pp. 234-250, 2012.

[8] I. Sermet-Gaudelus, M. L. Bianchi, M. Garabédian et al., "European cystic fibrosis bone mineralisation guidelines," Journal of Cystic Fibrosis, vol. 10, Suppl 2, pp. S16-S23, 2011.

[9] J. L. Hankinson, J. R. Odencrantz, and K. B. Fedan, "Spirometric reference values from a sample of the general U.S. population," American Journal of Respiratory and Critical Care Medicine, vol. 159, no. 1, pp. 179-187, 1999. 
[10] M. R. Miller, J. Hankinson, V. Brusasco et al., "Standardisation of spirometry," European Respiratory Journal, vol. 26, no. 2, pp. 319-338, 2005.

[11] J. T. Schousboe, J. A. Shepherd, J. P. Bilezikian, and S. Baim, "Executive summary of the 2013 International Society for Clinical Densitometry Position Development Conference on bone densitometry," Journal of Clinical Densitometry, vol. 16, no. 4, pp. 455-466, 2013.

[12] "Assessment of fracture risk and its application to screening for postmenopausal osteoporosis. Report of a WHO Study Group," World Health Organization Technical Report Series, vol. 843, pp. 1-129, 1994.

[13] S. J. King, D. J. Topliss, T. Kotsimbos et al., "Reduced bone density in cystic fibrosis: $\Delta$ F508 mutation is an independent risk factor," The European Respiratory Journal, vol. 25, no. 1, pp. 54-61, 2005.

[14] S. Sheikh, S. Gemma, and A. Patel, "Factors associated with low bone mineral density in patients with cystic fibrosis," Journal of Bone and Mineral Metabolism, vol. 33, no. 2, pp. 180-185, 2014.

[15] C. Braun, J. Bacchetta, P. Braillon, R. Chapurlat, J. Drai, and P. Reix, "Children and adolescents with cystic fibrosis display moderate bone microarchitecture abnormalities: data from high-resolution peripheral quantitative computed tomography," Osteoporosis International, vol. 28, no. 11, pp. 31793188, 2017.

[16] S. Sharma, M. Jaksic, S. Fenwick, C. Byrnes, and T. Cundy, "Accrual of bone mass in children and adolescents with cystic fibrosis," The Journal of Clinical Endocrinology \& Metabolism, vol. 102, no. 5, pp. 1734-1739, 2017.

[17] A. Vrieze, M. H. de Greef, P. J. Wijkstra, and J. B. Wempe, "Low bone mineral density in COPD patients related to worse lung function, low weight and decreased fat-free mass," Osteoporosis International, vol. 18, no. 9, pp. 1197-1202, 2007.

[18] S. Lekamwasam, D. P. Trivedi, and K. T. Khaw, "An association between respiratory function and hip bone mineral density in older men: a cross-sectional study," Osteoporosis International, vol. 16, no. 2, pp. 204-207, 2005.

[19] E. F. Shead, C. S. Haworth, H. Barker, D. Bilton, and J. E. Compston, "Osteoclast function, bone turnover and inflammatory cytokines during infective exacerbations of cystic fibrosis," Journal of Cystic Fibrosis, vol. 9, no. 2, pp. 93-98, 2010.

[20] E. F. Shead, C. S. Haworth, E. Gunn, D. Bilton, M. A. Scott, and J. E. Compston, "Osteoclastogenesis during infective exacerbations in patients with cystic fibrosis," American Journal of Respiratory and Critical Care Medicine, vol. 174, no. 3, pp. 306-311, 2006.

[21] A. A. Ionescu, L. S. Nixon, W. D. Evans et al., "Bone density, body composition, and inflammatory status in cystic fibrosis," American Journal of Respiratory and Critical Care Medicine, vol. 162, no. 3, pp. 789-794, 2000.

[22] R. E. Grossmann, S. M. Zughaier, S. Liu, R. H. Lyles, and V. Tangpricha, "Impact of vitamin D supplementation on markers of inflammation in adults with cystic fibrosis hospitalized for a pulmonary exacerbation," European Journal of Clinical Nutrition, vol. 66, no. 9, pp. 1072-1074, 2012.

[23] M. F. Holick, N. C. Binkley, H. A. Bischoff-Ferrari et al., "Evaluation, treatment, and prevention of vitamin D deficiency: an Endocrine Society clinical practice guideline," The Journal of Clinical Endocrinology \& Metabolism, vol. 96, no. 7, pp. 1911-1930, 2011.
[24] R. M. Aris, P. A. Merkel, L. K. Bachrach et al., "Guide to bone health and disease in cystic fibrosis," The Journal of Clinical Endocrinology and Metabolism, vol. 90, no. 3, pp. 1888-1896, 2005.

[25] L. L. Wolfenden, S. E. Judd, R. Shah, R. Sanyal, T. R. Ziegler, and V. Tangpricha, "Vitamin D and bone health in adults with cystic fibrosis," Clinical Endocrinology, vol. 69, no. 3, pp. 374381, 2008

[26] M. P. Boyle, M. L. Noschese, S. L. Watts, M. E. Davis, S. E. Stenner, and N. Lechtzin, "Failure of high-dose ergocalciferol to correct vitamin D deficiency in adults with cystic fibrosis," American Journal of Respiratory and Critical Care Medicine, vol. 172, no. 2, pp. 212-217, 2005.

[27] A. C. Modi, C. S. Lim, N. Yu, D. Geller, M. H. Wagner, and A. L. Quittner, "A multi-method assessment of treatment adherence for children with cystic fibrosis," Journal of Cystic Fibrosis, vol. 5, no. 3, pp. 177-185, 2006.

[28] T. Daniels, L. Goodacre, C. Sutton, K. Pollard, S. Conway, and D. Peckham, "Accurate assessment of adherence: self-report and clinician report vs electronic monitoring of nebulizers," Chest, vol. 140, no. 2, pp. 425-432, 2011.

[29] I. Legroux-Gerot, S. Leroy, C. Prudhomme et al., "Bone loss in adults with cystic fibrosis: prevalence, associated factors, and usefulness of biological markers," Joint, Bone, Spine, vol. 79, no. 1, pp. 73-77, 2012.

[30] L. A. Mortensen, G. M. Chan, S. C. Alder, and B. C. Marshall, "Bone mineral status in prepubertal children with cystic fibrosis," The Journal of Pediatrics, vol. 136, no. 5, pp. 648-652, 2000.

[31] C. S. Haworth, A. M. Jones, J. E. Adams, P. L. Selby, and A. K. Webb, "Randomised double blind placebo controlled trial investigating the effect of calcium and vitamin D supplementation on bone mineral density and bone metabolism in adult patients with cystic fibrosis," Journal of Cystic Fibrosis, vol. 3, no. 4, pp. 233-236, 2004.

[32] V. Tangpricha, A. Kelly, A. Stephenson et al., "An update on the screening, diagnosis, management, and treatment of vitamin $\mathrm{D}$ deficiency in individuals with cystic fibrosis: evidencebased recommendations from the Cystic Fibrosis Foundation," The Journal of Clinical Endocrinology \& Metabolism, vol. 97, no. 4, pp. 1082-1093, 2012.

[33] W. R. Hunt, B. R. Helfman, N. A. McCarty, and J. M. Hansen, "Advanced glycation end products are elevated in cystic fibrosis-related diabetes and correlate with worse lung function," Journal of Cystic Fibrosis, vol. 15, no. 5, pp. 681-688, 2016.

[34] N. Napoli, M. Chandran, D. D. Pierroz, B. Abrahamsen, A. V. Schwartz, and S. L. Ferrari, "Mechanisms of diabetes mellitusinduced bone fragility," Nature Reviews Endocrinology, vol. 13, no. 4, pp. 208-219, 2017.

[35] D. Vashishth, G. J. Gibson, J. I. Khoury, M. B. Schaffler, J. Kimura, and D. P. Fyhrie, "Influence of nonenzymatic glycation on biomechanical properties of cortical bone," Bone, vol. 28, no. 2, pp. 195-201, 2001.

[36] H. Lu, D. Kraut, L. C. Gerstenfeld, and D. T. Graves, "Diabetes interferes with the bone formation by affecting the expression of transcription factors that regulate osteoblast differentiation," Endocrinology, vol. 144, no. 1, pp. 346352, 2003.

[37] N. Follak, I. Kloting, and H. Merk, "Bone healing in drill defects in spontaneously diabetic $\mathrm{BB} / \mathrm{OK}$ rats. $\mathrm{A}$ 
histomorphometric and biomechanical study," Der Unfallchirurg, vol. 107, no. 9, pp. 750-760, 2004.

[38] A. Gandhi, H. A. Beam, J. P. O'Connor, J. R. Parsons, and S. S. Lin, "The effects of local insulin delivery on diabetic fracture healing," Bone, vol. 37, no. 4, pp. 482-490, 2005.

[39] D. Vanderschueren, M. R. Laurent, F. Claessens et al., "Sex steroid actions in male bone," Endocrine Reviews, vol. 35, no. 6, pp. 906-960, 2014.

[40] M. S. Putman, C. E. Milliren, N. Derrico et al., "Compromised bone microarchitecture and estimated bone strength in young adults with cystic fibrosis," The Journal of Clinical Endocrinology \& Metabolism, vol. 99, no. 9, pp. 3399-3407, 2014. 


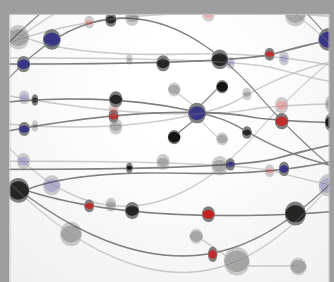

The Scientific World Journal
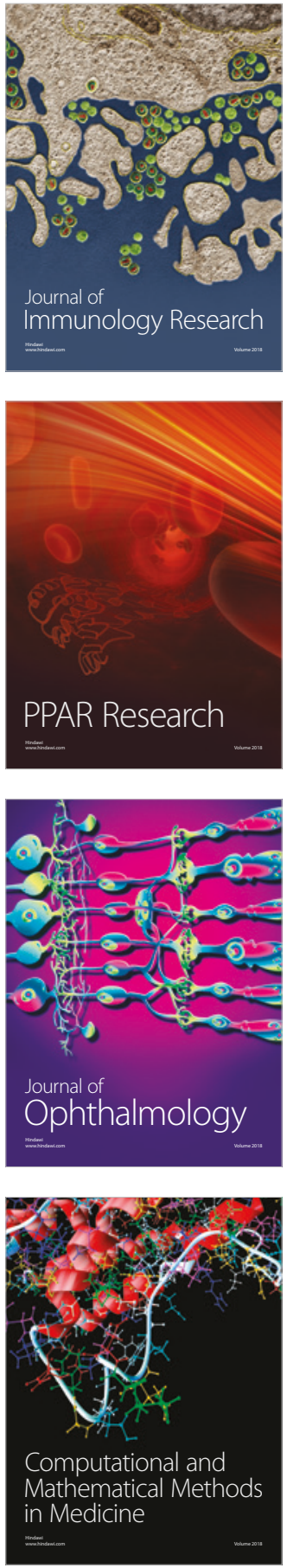

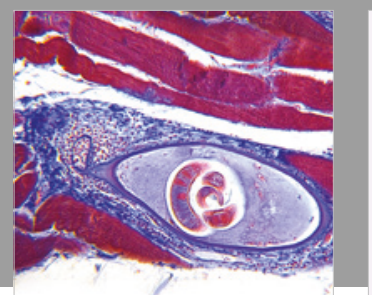

Gastroenterology Research and Practice

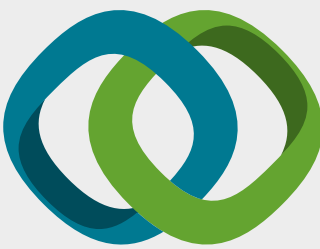

\section{Hindawi}

Submit your manuscripts at

www.hindawi.com
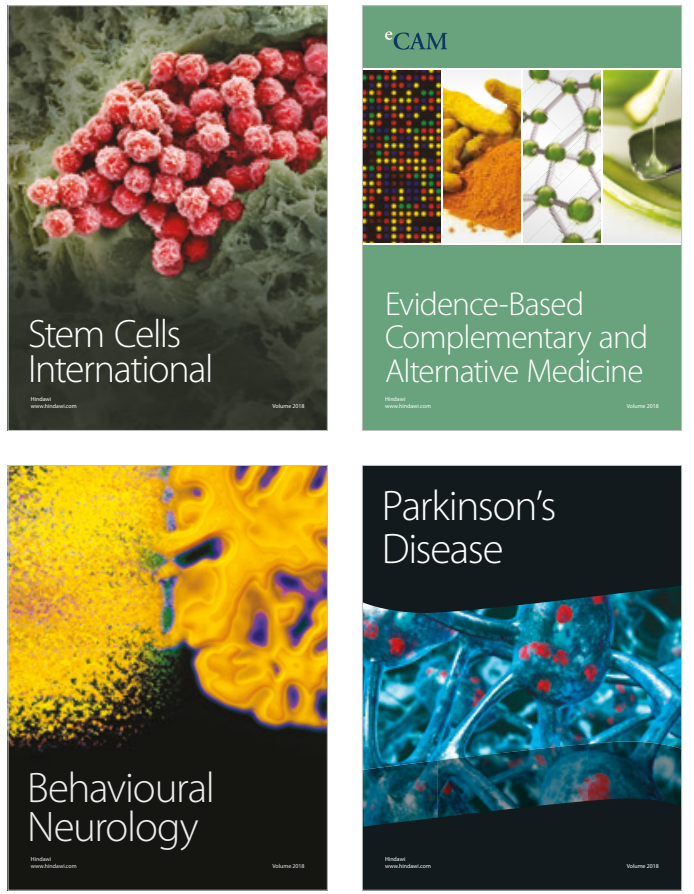

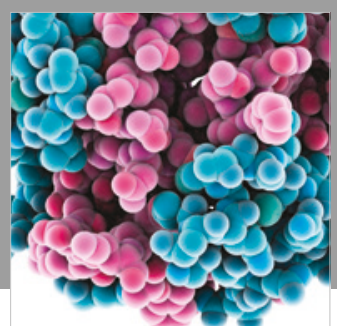

ournal of

Diabetes Research

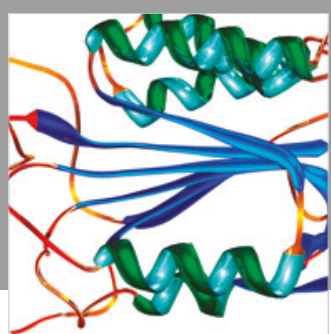

Disease Markers
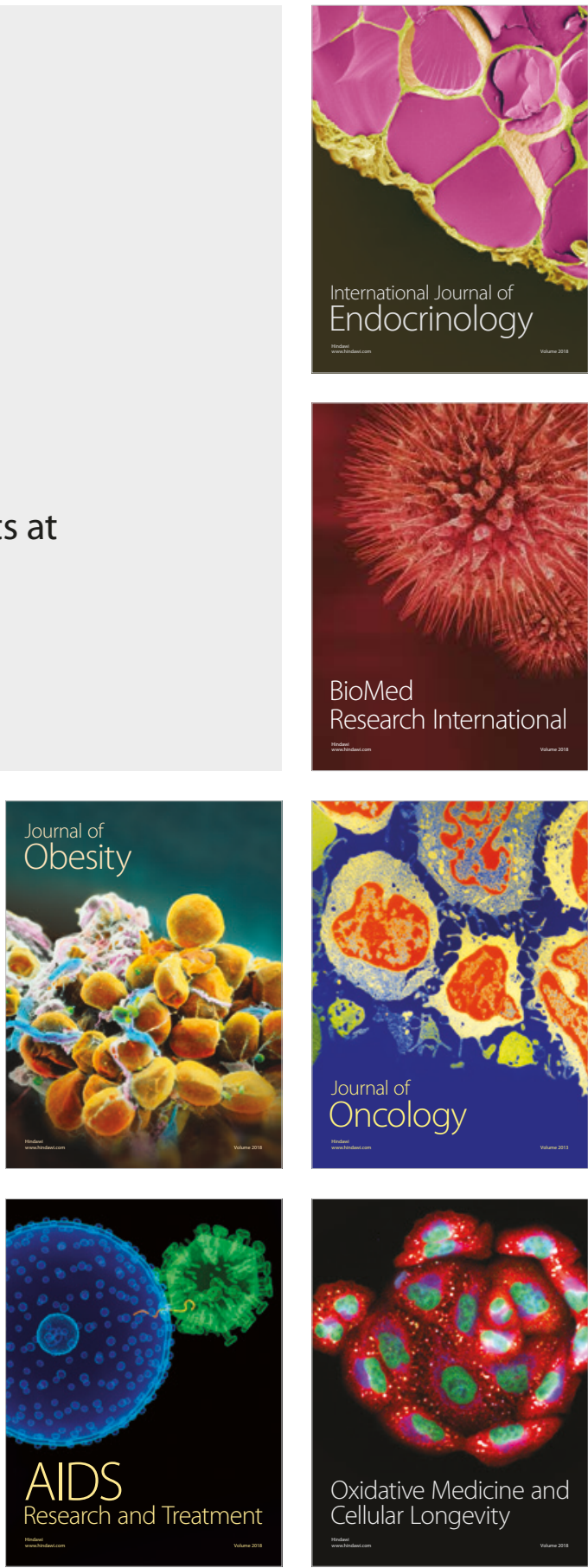